\title{
Formation and photochemistry of covalently bonded large functional PAH clusters
}

\author{
Junfeng Zhen ${ }^{1,2}$, Yuanyuan Yang ${ }^{1,2,3}$, Weiwei Zhang ${ }^{4}$, and Qingfeng Zhu ${ }^{1,2}$ \\ ${ }^{1}$ CAS Key Laboratory for Research in Galaxies and Cosmology, Department of Astronomy, University of Science and Technology \\ of China, Hefei 230026, PR China \\ e-mail: jfzhen@ustc.edu.cn \\ 2 School of Astronomy and Space Science, University of Science and Technology of China, Hefei 230026, PR China \\ 3 CAS Center for Excellence in Quantum Information and Quantum Physics, Hefei National Laboratory for Physical Sciences at the \\ Microscale, and Department of Chemical Physics, University of Science and Technology of China, Hefei 230026, PR China \\ ${ }^{4}$ Department of Mechanical and Nuclear Engineering, Pennsylvania State University, University Park, PA 16802, USA
}

Received 2 May 2019 / Accepted 13 July 2019

\begin{abstract}
Polycyclic aromatic hydrocarbon (PAH) molecules belong to a large and diverse chemical family in the interstellar medium (ISM). We study the formation and photochemistry of covalently bonded large functional PAH clusters, dicoronylene $\left(\mathrm{DC}, \mathrm{C}_{48} \mathrm{H}_{20}\right) / 9-$ vinylanthracene $\left(\mathrm{C}_{16} \mathrm{H}_{12}\right)$ and dicoronylene/9-methylanthracene $\left(\mathrm{C}_{15} \mathrm{H}_{12}\right)$ cluster cations, in the gas phase, and we offer an approach to the evolution of different types of large (covalently bonded) PAH clusters in the ISM. The experiments, which we combined with a quadrupole ion trap and time-of-flight mass spectrometry, show that large functional PAH cluster cations can form by gas-phase condensation through molecular-ion reactions. One group of functional PAH cluster cations contain the vinyl group $\left(-\mathrm{CHCH}_{2}\right)$, that is, from $\mathrm{C}_{16} \mathrm{H}_{12} \mathrm{DDC}^{+}$(e.g., $\mathrm{C}_{16} \mathrm{H}_{12} \mathrm{C}_{48} \mathrm{H}_{19}^{+}, m / z=799$ ) to $\left(\mathrm{C}_{16} \mathrm{H}_{12}\right)_{2} \mathrm{DDC}^{+}$(e.g., $\left.\left(\mathrm{C}_{16} \mathrm{H}_{12}\right)_{2} \mathrm{C}_{48} \mathrm{H}_{18}^{+}, m / z=1002\right)$. The other group of functional PAH cluster cations contain the methyl group $\left(-\mathrm{CH}_{3}\right)$, that is, from $\mathrm{C}_{15} \mathrm{H}_{12} \mathrm{DDC}^{+}\left(\mathrm{e} . \mathrm{g}\right.$., $\left.\mathrm{C}_{15} \mathrm{H}_{12} \mathrm{C}_{48} \mathrm{H}_{19}^{+}, m / z=787\right)$ to $\left(\mathrm{C}_{15} \mathrm{H}_{12}\right)_{2} \mathrm{DDC}^{+}$(e.g., $\left.\left(\mathrm{C}_{15} \mathrm{H}_{12}\right)_{2} \mathrm{C}_{48} \mathrm{H}_{18}^{+}, \mathrm{m} / z=990\right)$. With laser irradiation, the DC/9-vinylanthracene and DC/9-methylanthracene cluster cations show a very complicated dissociation process (e.g., dehydrogenation, $-\mathrm{CH}_{3}$ or $-\mathrm{CHCH}_{2}$ unit losses). We investigate the structure of newly formed PAH cluster cations, the bond energy, and the photodissociation energy for these reaction pathways with quantumchemical calculations. The obtained results provide a general molecular growth route toward large PAH cluster cations (e.g., functional PAH clusters) in a bottom-up formation process and the insight of the functional group (e.g., vinyl, $-\mathrm{C}_{2} \mathrm{H}_{3}$ and methyl, $-\mathrm{CH}_{3}$ ) effect on their evolutionary behavior. In addition, the studies of DC/9-vinylanthracene and DC/9-methylanthracene clusters (94-123 atoms, $\sim 2 \mathrm{~nm}$ in size) also provide a possible way of interpreting the formation processes of nanometer-sized grains in the ISM, especially when functional PAHs are included.
\end{abstract}

Key words. astrochemistry - methods: laboratory: molecular - molecular processes - ISM: molecules - ultraviolet: ISM

\section{Introduction}

Mid-infrared spectra of most objects in the interstellar medium (ISM) are dominated by broad features $(3.3,6.2,7.7,8.6$, and $11.2 \mu \mathrm{m}$ ) such as the aromatic infrared bands (AIBs). These IR vibrational signature features are generally attributed to IR fluorescence of large (50-100 C-atoms) polycyclic aromatic hydrocarbon (PAH) molecules and their derivatives (Tielens 2008, and references therein). Interstellar IR spectra also show evidence of PAH clusters and very small dust grains (Sellgren 1984; Rapacioli et al. 2005; Berné et al. 2007; Pilleri et al. 2012). These PAH species are found to be ubiquitous and abundant They contain $10 \%$ of the elemental carbon in space and are thought of as the key contributors to the energy and ionization balance of the gas in the ISM (Puget \& Léger 1989; Allamandola et al. 1989; Tielens 2013; Montillaud et al. 2013).

Large PAH molecules are thought to be formed in processes similar to soot formation in the cooling ejecta of carbonrich red giant stars as they flow from the stellar photosphere into the ISM of the Milky Way (Frenklach \& Feigelson 1989; Cherchneff et al. 1992; Croiset et al. 2016). PAHs can further be processed for some hundred million years in the harsh environment of the ISM. As part of this chemical evolution, PAHs may acquire functional groups and functionalize, such as methyl $\left(-\mathrm{CH}_{3}\right)$, vinyl $\left(-\mathrm{CHCH}_{2}\right)$, methoxy $\left(-\mathrm{OCH}_{3}\right)$, amino $\left(-\mathrm{NH}_{2}\right)$, cyano/isocyano $(-\mathrm{CN},-\mathrm{NC})$, acid $(-\mathrm{COOH})$, and hydroxyl $(-\mathrm{OH})$ (Hollenbach \& Tielens 1999). Experimental studies have shown that $\mathrm{PAH}$ mixture irradiates with some other small molecule (e.g., $\mathrm{CO}, \mathrm{H}_{2} \mathrm{O}$ ) in interstellar ice at a very low temperature (e.g., 10-50 K) that is analogous to ultraviolet light (e.g., $121.6 \mathrm{~nm}, \mathrm{Ly} \alpha, 10.2 \mathrm{eV}$ ) or high-energy particles, which gives rise to the addition functional groups of PAHs (Bernstein et al. 1999, 2002; Cook et al. 2015; Kofman et al. 2017). Moreover, upon heating of these ice mantles in regions of star and planet formation, the functionalized PAHs evaporate with the ice and are then thought to be further processed (e.g., photodissociation) by abundant ultraviolet (UV) photons from nearby luminous stars. Driven by this astrophysical interest, early studies have analyzed the photolytic behavior of functionalized PAHs based upon molecular bond energies (Geballe et al. 1989). Experiments focusing on the photoexcitation of functionalized PAHs have attracted much interest in recent years (Zhen et al. 2016; Chen et al. 2018). Particularly, processes that change the nature of the carbon skeleton have been a topic of recent studies because carbon skeleton modification may offer a way to form 

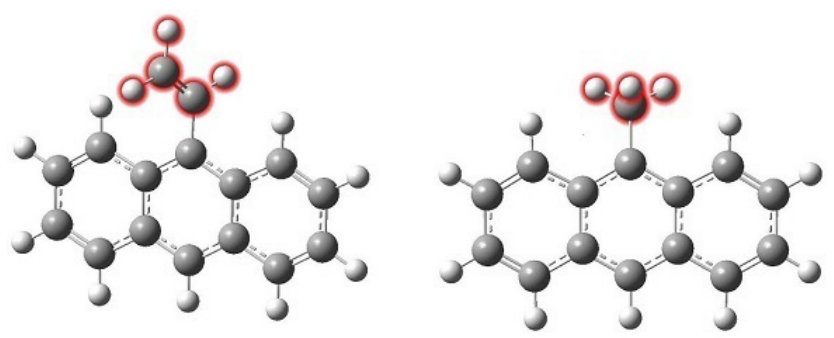

9-Vinylanthracene $\left(\mathrm{C}_{16} \mathrm{H}_{12}\right)$

9-Methylanthracene

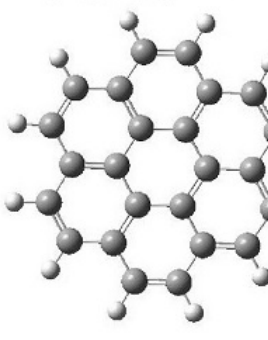
$\left(\mathrm{C}_{15} \mathrm{H}_{12}\right)$

Dicoronylene

(DC, $\mathrm{C}_{48} \mathrm{H}_{20}$ )

Fig. 1. Molecular geometry of 9-vinylanthracene $\left(\mathrm{C}_{16} \mathrm{H}_{12}\right)$, 9methylanthracene $\left(\mathrm{C}_{15} \mathrm{H}_{12}\right)$, and dicoronylene $\left(\mathrm{DC}, \mathrm{C}_{48} \mathrm{H}_{20}\right)$.

species that might act as building blocks of cages and fullerenes (Chuvilin et al. 2010; Pietrucci \& Andreoni 2014).

It is clear that partial interstellar PAHs contain functional groups (Bernstein et al. 2002). This species contains highly active reaction centers that will affect the photodissociation efficiency and photoisomerization process (Bernstein et al. 2002; Walsh 2008; Zhen et al. 2016). That is, functional groups will also affect the formation and photochemistry process of $\mathrm{PAH}$ clusters, and therefore have to be considered as well. However, little information is available on how the functional groups affect the formation and photoevolution of $\mathrm{PAH}$ cluster cations.

We have recently explored dicoronylene (DC, $\left.\mathrm{C}_{48} \mathrm{H}_{20}\right) /$ anthracene $\left(\mathrm{C}_{14} \mathrm{H}_{10}\right)$ and hexa-peri-hexabenzocoronene (HBC, $\left.\mathrm{C}_{42} \mathrm{H}_{18}\right)$ /anthracene $\left(\mathrm{C}_{14} \mathrm{H}_{10}\right)$ cluster cations (Zhen 2019; Zhen et al. 2019). They revive an efficient formation process of large molecules ( 100 atoms, e.g., PAH clusters or graphene) under laser irradiation. In order to characterize the effect of functional group on the formation (reactivity) and photostability behavior of PAH cluster cations, we here present a systematic study of methyl- and vinyl-substituted derivatives of anthracene, 9-methylanthracene $\left(\mathrm{C}_{15} \mathrm{H}_{12}\right)$, and 9-vinylanthracene $\left(\mathrm{C}_{16} \mathrm{H}_{12}\right)$ with dicoronylene (DC, $\mathrm{C}_{48} \mathrm{H}_{20}$ ) using a quadrupole mass filter (quadrupole ion trap) time-of-flight (QMF-QIT-TOF) mass spectrometry setup. In order to test the main hypothesis to interpret the obtained mass spectra, quantumchemical calculations are carried out on these relatively large compounds. We have selected 9-methylanthracene and 9-vinylanthracene as examples of functional PAHs, as shown in Fig. 1, for this study because these two are of potential astrophysical interest (Tielens 2005), and because their vapor pressure at room temperature is relatively high.

This paper is organized as follows: The experimental techniques are described in Sect. 2, the experimental and theoretical results are analyzed and discussed in Sects 3 and 4, and the astronomical implications of the results are illustrated in Sect. 5. A brief conclusion is provided in Sect. 6.

\section{Experimental methods}

The experiments and the information on experimental procedures are available in Zhen et al. (2019). We briefly recall the relevant detail here. DC is evaporated by heating the powder (Kentax, with purity better than 99.5\%) in the oven at a temperature of $\sim 633 \mathrm{~K}$. Subsequently, evaporated molecules are ionized using electron impact ionization, and they are transported into the ion trap through an ion gate and quadrupole mass filter. A second oven (neutral molecules source, $\sim 300 \mathrm{~K}$ ) is located below the trap so that the vapor-phase molecules (9-vinylanthracene or 9-methylanthracene power, J\&K, with purity better than 99\%) effuse continuously toward the center of the trap. In the trap, PAH cluster cations are formed by collision reaction between cations and neutral molecule. Helium gas is introduced continuously into the trap to thermalize the ion cloud through collisions with a leak valve. Adduct formation presumably occurs under our experimental operating conditions, possibly assisted by collisional stabilization of the chemically bonded intermediate complex by helium atoms. The third harmonic of an Nd:YAG laser (INDI, Spectra-Physics), $355 \mathrm{~nm}, \sim 6 \mathrm{~ns}$, operated at $10 \mathrm{~Hz}$, is used to irradiate newly formed ion clusters that are trapped. A beam shutter (Uniblitz, XRS-4) acts as a physical shield inside in the chamber and determines the interaction time of the light with the trapped ion clusters. The shutter is externally triggered to guarantee that the ion cloud is irradiated only for a specified amount of time during each cycle. A high-precision delay generator (SRS DG535) controls the full timing sequence.

Our setup operated at a typical frequency of $0.2 \mathrm{~Hz}$, that is, one full measuring cycle lasted $5 \mathrm{~s}$. At the leading edge of the master trigger, the ion gate opened $(0-4.0 \mathrm{~s})$, allowing the ion trap to fill with a certain amount of ions. In this period, the trapped ions reacted with 9-vinylanthracene or 9-methylanthracene molecules to form new cluster cations. Then after a short time-delay $(\sim 0.2 \mathrm{~s})$, the beam shutter opened and the ion cloud was irradiated $(4.2-4.8 \mathrm{~s})$. At the end of the irradiation, a negative square pulse $(4.88 \mathrm{~s})$ was applied to the end cap of the ion trap, accelerating the ions out of the trap and into the field-free TOF region where the resulting mass fragments were measured. The resulting mass spectra are shown in Fig. 2 for DC/9-vinylanthracene cluster cations and Fig. 3 for DC/9-methylanthracene cluster cations.

\section{Experimental results and discussion}

A typical mass spectrum of DC/9-vinylanthracene cluster cations without laser irradiation is shown in Fig. 2A. A series of DC/9-vinylanthracene cluster cations were produced, similarly to what was observed for DC/anthracene in Zhen (2019). In addition to the main DC mass peak $\left(\mathrm{C}_{48} \mathrm{H}_{20}, \mathrm{~m} / z=596\right)$, some mainly residual DC fragments are also measured, such as $\mathrm{C}_{48} \mathrm{H}_{16 / 17 / 18 / 19}^{+}, m / z=592,593,594$, and 595, which are dehydrogenated DC (DDC) cations, generated from the electron impact ionization (Zhen et al. 2015). We only considered these fragments in the reaction pathway. The DC/9-vinylanthracene (covalently bonded) cluster cations are labeled in detail in a zoomed-in mass spectrum in Fig. 2A. The theoretical results we describe below provide a very good justification for the PAH clusters, which react to form covalently bound cluster cations in the experiments. The inset spectrum provides more detail on the newly formed DC/9-vinylanthracene cluster cations: all of them are dehydrogenated, that is, partially $\mathrm{H}$-stripped ion species are the most abundant species, that is, $\mathrm{C}_{16} \mathrm{H}_{12} \mathrm{DDC}^{+}$ (e.g., $\left.\mathrm{C}_{16} \mathrm{H}_{12} \mathrm{C}_{48} \mathrm{H}_{19}^{+}, m / z=799\right)$ and $\left(\mathrm{C}_{16} \mathrm{H}_{12}\right)_{2} \mathrm{DDC}^{+}$(e.g., 

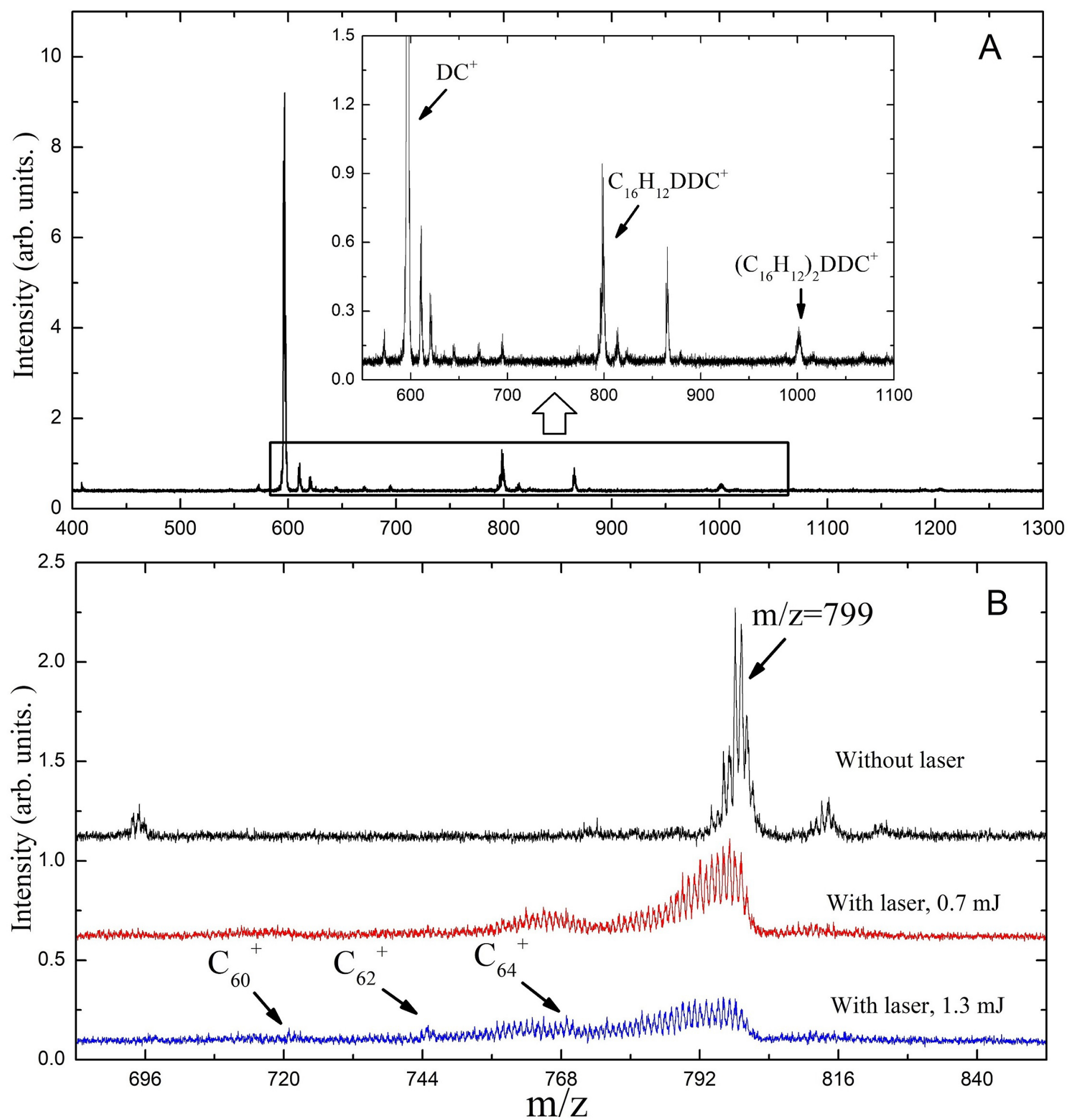

Fig. 2. Panel A: mass spectrum of DC/9-vinylanthracene cluster cations trapped in QIT without laser irradiation. The inset is a zoom-in of the mass spectrum, revealing newly formed clusters: $\mathrm{C}_{16} \mathrm{H}_{12} \mathrm{DDC}^{+}$and $\left(\mathrm{C}_{16} \mathrm{H}_{12}\right)_{2} \mathrm{DDC}^{+}$. Panel B: mass spectrum of DC/9-vinylanthracene cluster cations trapped in QIT with and without laser irradiation upon $355 \mathrm{~nm}$ irradiation at 0.7 and $1.3 \mathrm{~mJ}$ laser energy (the irradiation times were $0.6 \mathrm{~s}$, from $4.2-4.8 \mathrm{~s})$.

$\left.\left(\mathrm{C}_{16} \mathrm{H}_{12}\right)_{2} \mathrm{C}_{48} \mathrm{H}_{18}^{+}, m / z=1002\right)$. In addition, we also observed one additional peak $(\mathrm{m} / \mathrm{z}=864)$, although no assignments can be provided. We assume that this peak formed as a side-product and was caused by contamination in the ion trap chamber.

Based on our previous work in Zhen (2019) and Zhen et al. (2019), we propose that DC/9-vinylanthracene cluster cations are formed through formation reaction between DC dehydrogenation fragmented cations and neutral 9-vinylanthracene molecules. This occurs in a step-by-step reaction pathway. We show the formation reaction pathway for $\mathrm{C}_{16} \mathrm{H}_{12} \mathrm{DDC}^{+}$and $\left(\mathrm{C}_{16} \mathrm{H}_{12}\right)_{2} \mathrm{DDC}^{+}$below (Eqs. (1) and (2)):

$\mathrm{C}_{16} \mathrm{H}_{12}+\mathrm{DDC}^{+} \longrightarrow \mathrm{C}_{16} \mathrm{H}_{12} \mathrm{DDC}^{+}$

$\mathrm{C}_{16} \mathrm{H}_{12}+\mathrm{C}_{16} \mathrm{H}_{12} \mathrm{DDC}^{+} \longrightarrow\left(\mathrm{C}_{16} \mathrm{H}_{12}\right)_{2} \mathrm{DDC}^{+}$.

Figure 2B shows the resulting mass spectrum of trapped DC/9vinylanthracene cluster cations upon $355 \mathrm{~nm}$ irradiation at 0.7 

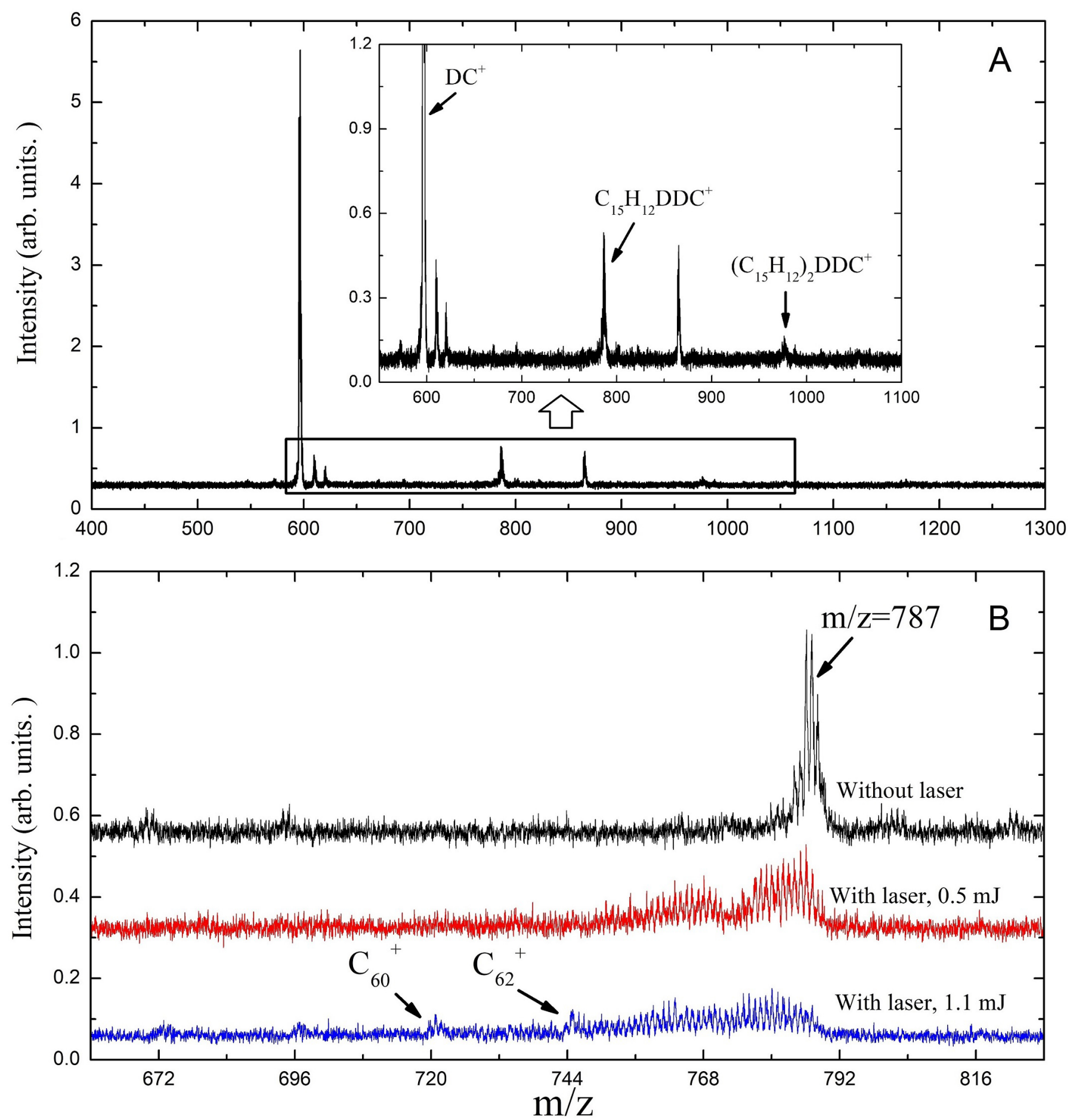

Fig. 3. Panel A: mass spectrum of DC/9-methylanthracene cluster cations trapped in QIT without laser irradiation. The inset is a zoom-in of the mass spectrum, revealing newly formed clusters: $\mathrm{C}_{15} \mathrm{H}_{12} \mathrm{DDC}^{+}$and $\left(\mathrm{C}_{15} \mathrm{H}_{12}\right)_{2} \mathrm{DDC}^{+}$. Panel $\mathrm{B}$ : mass spectrum of DC/9-methylanthracene cluster cations trapped in QIT with and without laser irradiation upon $355 \mathrm{~nm}$ irradiation at 0.5 and $1.1 \mathrm{~mJ}$ laser energy (the irradiation times were $0.6 \mathrm{~s}$, from $4.2-4.8 \mathrm{~s})$.

and $1.3 \mathrm{~mJ}$ laser energy (the irradiation times were $0.6 \mathrm{~s}$; i.e., typically about six pulses, from $4.2-4.8 \mathrm{~s}$ ). Upon laser irradiation, the mass spectra reveal a variety of fragmented ions. The dehydrogenation and carbon-unit loss behavior are illustrated, and the terminal photofragmentation pattern clearly depends directly on the incident radiation flux.

The observed fragmentation trend shows that at low energy (e.g., $0.7 \mathrm{~mJ}$, red line), the DC/9-vinylanthracene cluster cations dehydrogenated, together with $\mathrm{C}_{2} \mathrm{H}_{3}$ loss, and they continue with a higher degree of dehydrogenation. With increasing laser energy (e.g., $1.3 \mathrm{~mJ}$, blue line), the peaks due to multiple fragmentation steps become more prominent and some graphene products (e.g., $\mathrm{C}_{60}^{+}, \mathrm{C}_{62}^{+}$and $\mathrm{C}_{64}^{+}$, blue line) become accessible. The photochemical behavior in these two spectra suggests that after direct dehydrogenation or loss of its $\mathrm{C}_{2} \mathrm{H}_{3}$ unit and then with further dehydrogenation, DC/9-vinylanthracene 
cluster cations convert into aromatic species (Castellanos et al. 2018; West et al. 2018).

Based on this discussion, we propose a photodissociation channel upon laser irradiation for $\mathrm{C}_{16} \mathrm{H}_{12} \mathrm{DDC}$ (e.g., $\mathrm{C}_{16} \mathrm{H}_{12} \mathrm{C}_{48} \mathrm{H}_{19}^{+}$) cluster cations as shown below (Eqs. (3)-(6)). We discuss the structure intended for these large molecules in the next section with the theoretical calculations.

$$
\begin{aligned}
& \mathrm{C}_{16} \mathrm{H}_{12} \mathrm{C}_{48} \mathrm{H}_{19}{ }^{+}+h v \longrightarrow \mathrm{C}_{16} \mathrm{H}_{11} \mathrm{C}_{48} \mathrm{H}_{19}{ }^{+}+\mathrm{H} \\
& \mathrm{C}_{16} \mathrm{H}_{11} \mathrm{C}_{48} \mathrm{H}_{19}{ }^{+}+h v \longrightarrow \mathrm{C}_{64} \mathrm{H}_{n}{ }^{+}, n=[0-30] \\
& \mathrm{C}_{16} \mathrm{H}_{12} \mathrm{C}_{48} \mathrm{H}_{19}{ }^{+}+h v \longrightarrow \mathrm{C}_{14} \mathrm{H}_{9} \mathrm{C}_{48} \mathrm{H}_{19}{ }^{+}+\mathrm{C}_{2} \mathrm{H}_{3} \\
& \mathrm{C}_{14} \mathrm{H}_{9} \mathrm{C}_{48} \mathrm{H}_{19}{ }^{+}+h v \longrightarrow \mathrm{C}_{62} \mathrm{H}_{m}{ }^{+}, m=[0-28] .
\end{aligned}
$$

A typical mass spectrum of DC/9-methylanthracene (covalently bonded) cluster cations without laser irradiation is shown in Fig. 3A. A series of DC/9-methylanthracene cluster cations is produced, similarly to what was observed for DC/anthracene in Zhen (2019) and for DC/9-vinylanthracene cluster cations as shown above. The DC/9-methylanthracene cluster cations are labeled in detail in a zoomed-in mass spectrum in Fig. 3A. The inset spectrum provides more detail on the newly formed DC/9-methylanthracene cluster cations: all of them are dehydrogenated, i.e., partially $\mathrm{H}$-stripped ion species are the most abundant species, that is $\mathrm{C}_{15} \mathrm{H}_{12} \mathrm{DDC}^{+}$(e.g., $\mathrm{C}_{15} \mathrm{H}_{12} \mathrm{C}_{48} \mathrm{H}_{19}^{+}, m / z=$ $787)$ and $\left(\mathrm{C}_{15} \mathrm{H}_{12}\right)_{2} \mathrm{DDC}^{+}$(e.g., $\left.\left(\mathrm{C}_{15} \mathrm{H}_{12}\right)_{2} \mathrm{C}_{48} \mathrm{H}_{18}^{+}, \mathrm{m} / z=978\right)$. Similar to the DC/9-vinylanthracene cluster cations experiments, we also observed one additional peak $(\mathrm{m} / \mathrm{z}=864)$, although no assignments can be provided. We assume that this peak formed as a side-product and was caused by contamination in the ion trap chamber.

Based on our previous work in Zhen (2019) and Zhen et al. (2019), we propose that DC/9-methylanthracene cluster cations are formed through a formation reaction between DC dehydrogenation fragmented cations and neutral 9-methylanthracene molecules and that it occurs in a step-by-step reaction pathway. We show the formation reaction pathway for $\mathrm{C}_{15} \mathrm{H}_{12} \mathrm{DDC}^{+}$and $\left(\mathrm{C}_{15} \mathrm{H}_{12}\right)_{2} \mathrm{DDC}^{+}$below (Eqs. (7) and (8)):

$\mathrm{C}_{15} \mathrm{H}_{12}+\mathrm{DDC}^{+} \longrightarrow \mathrm{C}_{15} \mathrm{H}_{12} \mathrm{DDC}^{+}$

$\mathrm{C}_{15} \mathrm{H}_{12}+\mathrm{C}_{15} \mathrm{H}_{12} \mathrm{DDC}^{+} \longrightarrow\left(\mathrm{C}_{15} \mathrm{H}_{12}\right)_{2} \mathrm{DDC}^{+}$.

Figure $3 \mathrm{~B}$ shows the resulting mass spectrum of trapped DC/9methylanthracene cluster cations upon $355 \mathrm{~nm}$ irradiation at 0.5 and $1.1 \mathrm{~mJ}$ laser energy (the irradiation times were $0.6 \mathrm{~s}$; i.e., typically about six pulses, from 4.2-4.8 s). Upon laser irradiation, the mass spectra reveal a variety of fragment ions. The dehydrogenation and carbon-unit loss behavior are illustrated, and the terminal photofragmentation pattern clearly depends directly on the incident radiation flux.

The observed trend shows that at low energy (e.g., $0.5 \mathrm{~mJ}$, red line), the DC/9-methylanthracene cluster cations dehydrogenated, together with $\mathrm{CH}_{3}$ loss, and they continue with a higher degree of dehydrogenation. With increasing laser energy (e.g., $1.1 \mathrm{~mJ}$, blue line), the peaks due to multiple fragmentation steps become more prominent, and some graphene products (e.g., $\mathrm{C}_{60}^{+}$and $\mathrm{C}_{62}^{+}$, blue line) become accessible. The photochemical behavior in these two spectra suggests that after direct dehydrogenation or loss of its $\mathrm{CH}_{3}$ unit and then with further dehydrogenation, DC/9-methylanthracene cluster cations convert into aromatic species (Castellanos et al. 2018; West et al. 2018).

Based on this discussion, we propose a photodissociation channel upon laser irradiation for $\mathrm{C}_{15} \mathrm{H}_{12} \mathrm{DDC}$ (e.g., $\mathrm{C}_{15} \mathrm{H}_{12} \mathrm{C}_{48} \mathrm{H}_{19}^{+}$) cluster cations as shown below (Eqs. (9)-(12)).
We discuss the structure intended for these large molecules in the next section with the theoretical calculations.

$$
\begin{aligned}
& \mathrm{C}_{15} \mathrm{H}_{12} C_{48} \mathrm{H}_{19}{ }^{+}+h v \longrightarrow \mathrm{C}_{15} \mathrm{H}_{11} \mathrm{C}_{48} \mathrm{H}_{19}{ }^{+}+\mathrm{H} \\
& \mathrm{C}_{15} \mathrm{H}_{11} \mathrm{C}_{48} \mathrm{H}_{19}{ }^{+}+h v \longrightarrow \mathrm{C}_{63} \mathrm{H}_{n}{ }^{+}, n=[0-30] \\
& \mathrm{C}_{15} \mathrm{H}_{12} C_{48} \mathrm{H}_{19}{ }^{+}+h v \longrightarrow \mathrm{C}_{14} \mathrm{H}_{9} \mathrm{C}_{48} \mathrm{H}_{19}{ }^{+}+\mathrm{CH}_{3} \\
& \mathrm{C}_{14} \mathrm{H}_{9} \mathrm{C}_{48} \mathrm{H}_{19}{ }^{+}+h v \longrightarrow \mathrm{C}_{62} \mathrm{H}_{m}{ }^{+}, m=[0-28] .
\end{aligned}
$$

\section{Results of the theoretical calculation and discussion}

We observed a series of mass peaks, as shown in Figs. 2 and 3, and we employed quantumchemistry to link these observations to the structures of these peaks and identify the possible formation and photodissociation pathways because peaks in a mass spectrum can refer to more than one isomer, and it is difficult to infer reaction products and pathways from the experiments alone. To interpret the experimental data, we therefore further investigated them with density functional theory (DFT) calculations. The theoretical calculations were carried out with the hybrid density functional B3LYP (Becke 1992; Lee et al. 1988) as implemented in the Gaussian 16 program (Frisch et al. 2015). The basis set of $6-311++G(d, p)$ was used for all calculations. To account for the intermolecular interaction, we also considered a dispersion correction (D3, Grimme et al. 2011) for each system. Our results do not include the basis set-superposition error (BSSE) correction, which usually results in slightly reduced bond energies (Basiuk \& Tahuilan-Anguiano 2019).

We carried out theoretical calculations for the DC/9methylanthracene and DC/9-vinylanthracene cluster cations system, and we illustrate each system in detail and discuss the functional group effect. In addition, we also performed the theoretical calculations for the DC/anthracene cluster cation system. Its formation and photofragmentation behavior has been studied in detail before in Zhen (2019). Therefore, it is possible to compare the functional PAH clusters obtained here (sitesubstituted PAH cluster cations) with the normal PAH cluster cations reported earlier.

\subsection{DC/anthracene cluster cation system}

The results for the DC/anthracene cluster cation system have been presented in Zhen (2019). We show the optimized carbon skeletons after the theoretical calculations, as we did in Zhang et al. (2019), in Fig. 4. $\mathrm{C}_{14} \mathrm{H}_{10} \mathrm{DDC}^{+}$is a cationic cluster of mono-anthracene and DDC that is connected by one $\mathrm{C}-\mathrm{C}$ single bond. Here, DDC consists of dehydrogenated cations with different dehydrogenated level (i.e., $\mathrm{C}_{48} \mathrm{H}_{16 / 17 / 18 / 19}^{+}$). Accordingly, the cationic clusters are $\left[\mathrm{C}_{14} \mathrm{H}_{10}-\mathrm{C}_{48} \mathrm{H}_{19}\right]^{+}(\mathrm{m} / z=773)$, $\left[\mathrm{C}_{14} \mathrm{H}_{10}-\mathrm{C}_{48} \mathrm{H}_{18}\right]^{+}(m / z=772),\left[\mathrm{C}_{14} \mathrm{H}_{10}-\mathrm{C}_{48} \mathrm{H}_{17}\right]^{+}(\mathrm{m} / \mathrm{z}=$ $771)$, and $\left[\mathrm{C}_{14} \mathrm{H}_{10}-\mathrm{C}_{48} \mathrm{H}_{16}\right]^{+}(\mathrm{m} / z=770)$. For the $\mathrm{C}-\mathrm{C}$ single bond in the $\mathrm{C}_{14} \mathrm{H}_{10} \mathrm{DDC}^{+}$cluster, one carbon from DDC is in $\mathrm{sp}^{2}$ hybridization, and the other carbon from anthracene is in $\mathrm{sp}^{3}$ hybridization with an additional $\mathrm{C}-\mathrm{H}$ bond.

As one typical example, we discuss below the formation pathway of $\left[\mathrm{C}_{14} \mathrm{H}_{10}-\mathrm{C}_{48} \mathrm{H}_{19}\right]^{+}$, which is a cationic cluster consisting of neutral anthracene and $\mathrm{C}_{48} \mathrm{H}_{19}^{+}$. The five isomer structure of $\mathrm{C}_{48} \mathrm{H}_{19}^{+}$(five dehydrogenation sites) and the three positions of $\mathrm{C}_{14} \mathrm{H}_{10}$ mean that there are 15 possible reaction pathways. We present here one typical structure for $\mathrm{C}_{48} \mathrm{H}_{19}^{+}$and two typical positions for $\mathrm{C}_{14} \mathrm{H}_{10}$ (as shown in Fig. 4), with two more favorable possible reaction pathways and isomers $\left(\mathrm{P}_{1}\right.$ and $\left.\mathrm{P}_{2}\right)$. 

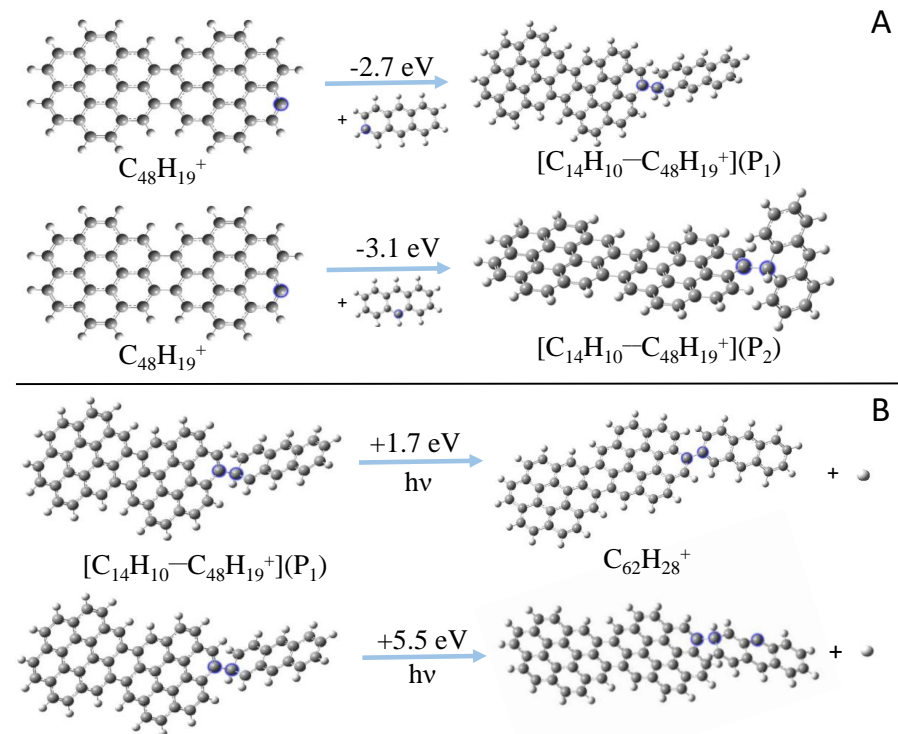

$\left[\mathrm{C}_{14} \mathrm{H}_{10}-\mathrm{C}_{48} \mathrm{H}_{19}{ }^{+}\right]\left(\mathrm{P}_{1}\right)$
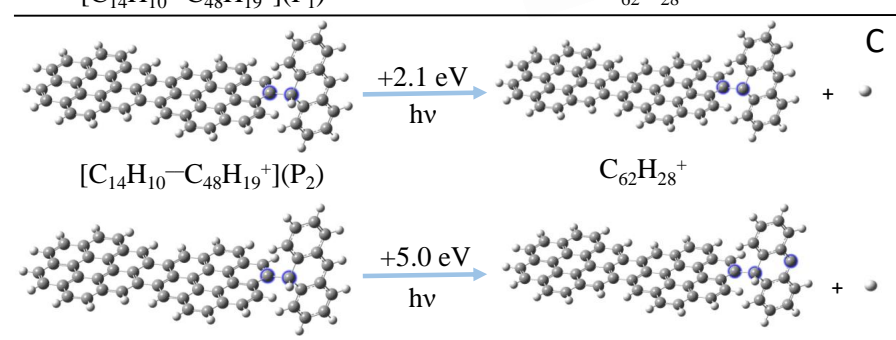

$\left[\mathrm{C}_{14} \mathrm{H}_{10}-\mathrm{C}_{48} \mathrm{H}_{19}{ }^{+}\right]\left(\mathrm{P}_{2}\right)$

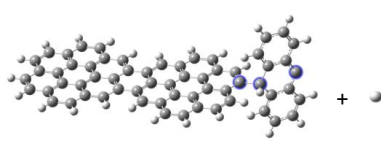

$\mathrm{C}_{62} \mathrm{H}_{28}{ }^{+}$

Fig. 4. Panel $A$ : formation reaction pathway for $\mathrm{C}_{14} \mathrm{H}_{10} \mathrm{DDC}^{+}$, e.g., $\mathrm{C}_{14} \mathrm{H}_{10} \mathrm{C}_{48} \mathrm{H}_{19}^{+}\left(\mathrm{P}_{1}\right.$ and $\left.\mathrm{P}_{2}\right)$. Panel $B$ : photodissociation pathway for $\mathrm{P}_{1}$. Panel C: photodissociation pathway for $\mathrm{P}_{2}$.

We present in Fig. 4A two possible reaction pathways and the optimized structures of $\left[\mathrm{C}_{14} \mathrm{H}_{10}-\mathrm{C}_{48} \mathrm{H}_{19}\right]^{+}$from the single $\mathrm{C}_{48} \mathrm{H}_{19}^{+}$and $\mathrm{C}_{14} \mathrm{H}_{10}$ to the cationic cluster of $\left[\mathrm{C}_{14} \mathrm{H}_{10}-\mathrm{C}_{48} \mathrm{H}_{19}\right]^{+}$ $\left(\mathrm{P}_{1}\right.$ and $\left.\mathrm{P}_{2}\right)$. Clearly, all the reactions are exothermic, with -2.7 $\mathrm{eV}$ for $\mathrm{P}_{1}$ and $-3.1 \mathrm{eV}$ for $\mathrm{P}_{2}$. The formation pathway of $\mathrm{P}_{2}$ has a lower energy than that for $\mathrm{P}_{1}$ possibly because the single-H C atoms in anthracene are much more reactive than other $\mathrm{C}$-atoms (Zhen et al. 2019). The formation energy is similar, and we also considered that the DC/anthracene cluster cations, which we produced through an ion-molecular reaction, are a mixture of components with all possible 15 different isomers.

In the subsequent photodissociation pathway, we calculated two channels for $\left(\mathrm{C}_{14} \mathrm{H}_{10} \mathrm{DDC}^{+}, \mathrm{P}_{1}\right)$, as shown in Fig. 4B. The dissociation energy is $1.7 \mathrm{eV}$ for $\mathrm{H}$ loss from the aliphatic carbon, which is the dominant dissociation channel for $\mathrm{P}_{1}$. In contrast, $\mathrm{H}$ loss from the pure aromatic carbon rings located in anthracene molecules group takes around $5.5 \mathrm{eV}$ (Chen et al. 2015; West et al. 2018). As shown in Fig. 4C, we also calculated two dissociation channels for $\left(\mathrm{C}_{14} \mathrm{H}_{10} \mathrm{DDC}^{+}, \mathrm{P}_{2}\right)$. The dissociation energy is $2.1 \mathrm{eV}$ for $\mathrm{H}$ loss from the aliphatic carbon, which is the dominant dissociation channel for $\mathrm{P}_{2}$. In contrast, $\mathrm{H}$ loss from the pure aromatic carbon rings located in anthracene molecules group takes around $5.0 \mathrm{eV}$ (Chen et al. 2015). The obtained dissociation energies for DC/anthracene cluster cations are similar to our previous result for fluorene cluster cations (Zhang et al. 2019).

On the basis of this discussion, we propose a photodissociation channel upon laser irradiation for $\mathrm{C}_{14} \mathrm{H}_{10} \mathrm{DDC}$ (e.g., $\left[\mathrm{C}_{14} \mathrm{H}_{10}-\mathrm{C}_{48} \mathrm{H}_{19}\right]^{+}$) cluster cations as shown below (equations
13). The calculation result agrees with the experimental observation reported in Zhen (2019),

$$
\begin{aligned}
& \mathrm{C}_{14} \mathrm{H}_{10} \mathrm{C}_{48} \mathrm{H}_{19}{ }^{+}+h v \longrightarrow \mathrm{C}_{14} \mathrm{H}_{9} \mathrm{C}_{48} \mathrm{H}_{19}{ }^{+}+\mathrm{H} \\
& \mathrm{C}_{14} \mathrm{H}_{9} \mathrm{C}_{48} \mathrm{H}_{19}{ }^{+}+h v \longrightarrow \mathrm{C}_{62} \mathrm{H}_{n}{ }^{+}, n=[0-28] .
\end{aligned}
$$

The continued dehydrogenation process for DC/anthracene cluster cations, for example, $\mathrm{C}_{62} \mathrm{H}_{28}^{+}\left(\left[\mathrm{C}_{14} \mathrm{H}_{9}-\mathrm{C}_{48} \mathrm{H}_{19}\right]^{+}\right)$formed from $\mathrm{P}_{1}$ or $\mathrm{P}_{2}$, which is first converted into large PAHs and then transformed into $\mathrm{C}_{60}^{+}$(graphene) upon irradiation, followed by full dehydrogenation (Eq. (14)) also agrees with the experimental observation reported in Zhen (2019).

\subsection{DC/9-vinylanthracene cluster cation system}

The DC/anthracene cluster cation, which is similar to the DC/9-vinylanthracene cluster cation system shown in Fig. 5, $\mathrm{C}_{16} \mathrm{H}_{12} \mathrm{DDC}^{+}$is a cationic cluster of mono-9-vinylanthracene and $\mathrm{DDC}$, connected by one $\mathrm{C}-\mathrm{C}$ single bond. Accordingly, the cationic clusters are $\left[\mathrm{C}_{16} \mathrm{H}_{12}-\mathrm{C}_{48} \mathrm{H}_{19}\right]^{+}(\mathrm{m} / \mathrm{z}=799)$, $\left[\mathrm{C}_{16} \mathrm{H}_{12}-\mathrm{C}_{48} \mathrm{H}_{18}\right]^{+}(m / z=798),\left[\mathrm{C}_{16} \mathrm{H}_{12}-\mathrm{C}_{48} \mathrm{H}_{17}\right]^{+}(\mathrm{m} / \mathrm{z}=$ $797)$, and $\left[\mathrm{C}_{16} \mathrm{H}_{12}-\mathrm{C}_{48} \mathrm{H}_{16}\right]^{+}(m / z=796)$. For the $\mathrm{C}-\mathrm{C}$ single bond in $\mathrm{C}_{16} \mathrm{H}_{12} \mathrm{DDC}^{+}$cluster, one carbon from DDC is in $\mathrm{sp}^{2}$ hybridization, and the other carbon from 9-vinylanthracene is in $\mathrm{sp}^{3}$ hybridization with an additional $\mathrm{C}-\mathrm{H}$ bond. The experimental formation reaction pathways of $\mathrm{C}_{16} \mathrm{H}_{12}$ DDC group cluster cations are shown in Eq. (1).

As one typical example, we discuss below the formation pathway of $\left[\mathrm{C}_{16} \mathrm{H}_{12}-\mathrm{C}_{48} \mathrm{H}_{19}\right]^{+}$, which is a cationic cluster consisting of a neutral 9-vinylanthracene and $\mathrm{C}_{48} \mathrm{H}_{19}^{+} \cdot \mathrm{C}_{48} \mathrm{H}_{19}^{+}$has a five-isomer structure and $\mathrm{C}_{16} \mathrm{H}_{12}$ has eight positions, which means that 40 reaction pathways are possible. We present one typical structure for $\mathrm{C}_{48} \mathrm{H}_{19}^{+}$and four typical positions for $\mathrm{C}_{16} \mathrm{H}_{12}$ here (as shown in Fig. 5A), with four more favorable possible reaction pathways and isomers $\left(\mathrm{P}_{1}, \mathrm{P}_{2}, \mathrm{P}_{3}\right.$, and $\left.\mathrm{P}_{4}\right)$.

We present in Fig. 5A the four possible reaction pathways of Eq. (1) and the optimized structures of $\left[\mathrm{C}_{16} \mathrm{H}_{12}-\mathrm{C}_{48} \mathrm{H}_{19}\right]^{+}$, that from $\mathrm{C}_{48} \mathrm{H}_{19}^{+}$and $\mathrm{C}_{16} \mathrm{H}_{12}$ to the cationic cluster of $\left[\mathrm{C}_{14} \mathrm{H}_{10}-\mathrm{C}_{48} \mathrm{H}_{19}\right]^{+}\left(\mathrm{P}_{1}, \mathrm{P}_{2}, \mathrm{P}_{3}\right.$ and $\left.\mathrm{P}_{4}\right)$, respectively. Clearly, all the reactions are exothermic, with $-2.8 \mathrm{eV}$ for $\mathrm{P}_{1},-3.3 \mathrm{eV}$ for $\mathrm{P}_{2},-2.9 \mathrm{eV}$ for $\mathrm{P}_{3}$, and $-3.5 \mathrm{eV}$ for $\mathrm{P}_{4}$. The formation pathway of $\mathrm{P}_{4}$ has the lowest energy all the formation pathways. A possible reason might be that the single$\mathrm{H} \mathrm{C}$ atoms in 9-vinylanthracene are much more reactive than other C-atoms (Zhen et al. 2019). The formation energy for DC/9-vinylanthracene cluster cations is similar to that of the DC/anthracene cluster. We therefore consider that the DC/9vinylanthracene cluster cations that we produced through the ion-molecular reaction are a mixture of components that include all possible 40 different isomers.

In the subsequent dissociation pathway, we calculated three dissociation channels for $\left(\mathrm{C}_{16} \mathrm{H}_{12} \mathrm{DDC}^{+}, \mathrm{P}_{1}\right)$, as shown in Fig. 5B. The dissociation energy is $1.7 \mathrm{eV}$ for $\mathrm{H}$ loss from the aliphatic carbon, which is the dominant dissociation channel for $\mathrm{P}_{1}$. In contrast, $\mathrm{H}$ loss from the vinyl group takes around $5.1 \mathrm{eV}$, and $\mathrm{CHCH}_{2}$ loss from the 9-vinylanthracene molecules group takes around $5.1 \mathrm{eV}$. As shown in Fig. 5C, we calculated one dissociation channel for $\left(\mathrm{C}_{16} \mathrm{H}_{12} \mathrm{DDC}^{+}, \mathrm{P}_{2}\right)$. The dissociation energy is $2.2 \mathrm{eV}$ for $\mathrm{H}$ loss from the aliphatic carbon, which is the dominant dissociation channel for $\mathrm{P}_{2}$. As shown in Fig. 5D, we also calculated one dissociation channel for $\left(\mathrm{C}_{16} \mathrm{H}_{12} \mathrm{DDC}^{+}\right.$, $\mathrm{P}_{3}$ ). The dissociation energy is $1.7 \mathrm{eV}$ for $\mathrm{CHCH}_{2}$ loss from the aliphatic carbon, which is the dominant dissociation channel for $\mathrm{P}_{3}$. As shown in Fig. 5E, we also calculated one dissociation channel for $\left(\mathrm{C}_{16} \mathrm{H}_{12} \mathrm{DDC}^{+}, \mathrm{P}_{4}\right)$. The dissociation energy is 

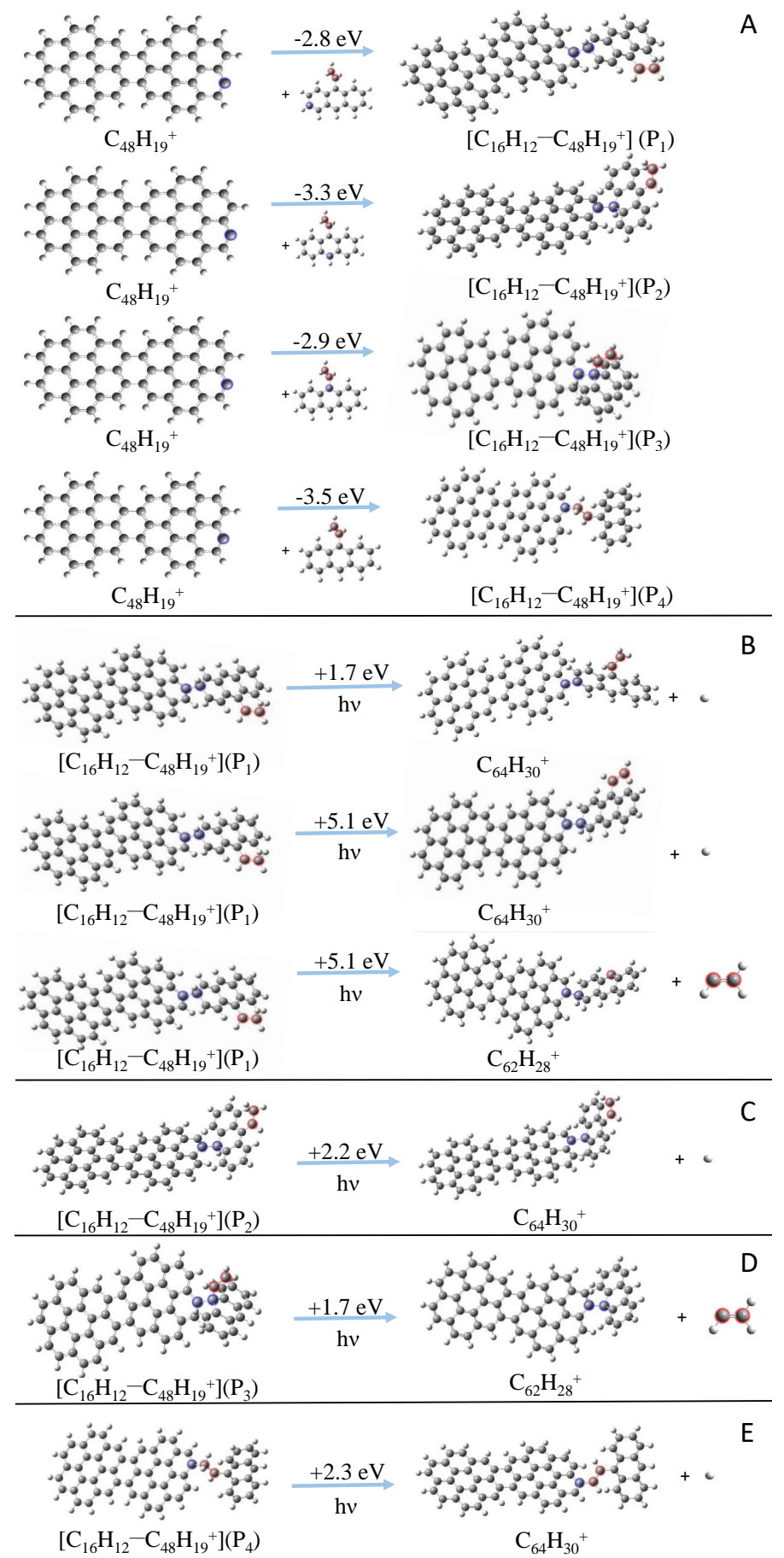

Fig. 5. Panel $A$ : formation reaction pathway for $\mathrm{C}_{16} \mathrm{H}_{12} \mathrm{DDC}^{+}$, e.g., $\mathrm{C}_{16} \mathrm{H}_{12} \mathrm{C}_{48} \mathrm{H}_{19}^{+}\left(\mathrm{P}_{1}, \mathrm{P}_{2}, \mathrm{P}_{3}\right.$ and $\left.\mathrm{P}_{4}\right)$. Panel $B$ : photodissociation pathway for $\mathrm{P}_{1}$. Panel $C$ : photodissociation pathway for $\mathrm{P}_{2}$. Panel $D$ : photodissociation pathway for $\mathrm{P}_{3}$. Panel $E$ : photodissociation pathway for $\mathrm{P}_{4}$.

$2.3 \mathrm{eV}$ for $\mathrm{H}$ loss from the vinyl group, which is the dominant dissociation channel for $\mathrm{P}_{4}$.

The lowest dissociation energy for each DC/9vinylanthracene cluster cation isomers is $\mathrm{H}$ loss with $1.7 \mathrm{eV}$ for $\mathrm{P}_{1}, \mathrm{H}$ loss with $2.2 \mathrm{eV}$ for $\mathrm{P}_{2}$, and $\mathrm{H}$ loss with $2.3 \mathrm{eV}$ for $\mathrm{P}_{4}$ for dissociation Eq. (3), $\mathrm{CHCH}_{2}$ loss with $1.7 \mathrm{eV}$ for $\mathrm{P}_{3}$ for dissociation Eq. (5). This agrees with the experimental results, which indicated that this is the dominant dissociation channel. The dissociation energy for DC/9-vinylanthracene cluster cations is similar to that of DC/anthracene and our previous fluorene cluster cation result (Zhang et al. 2019).

The continued dehydrogenation process for DC/9vinylanthracene cluster cations is shown in Fig. 5B-E. It shows that $\mathrm{C}_{64} \mathrm{H}_{30}^{+}\left(\left[\mathrm{C}_{16} \mathrm{H}_{11}-\mathrm{C}_{48} \mathrm{H}_{19}\right]^{+}\right)$forms from $\mathrm{P}_{1}, \mathrm{P}_{2}$, or $\mathrm{P}_{4}$ for experimental photodissociation Eq. (4), and $\mathrm{C}_{62} \mathrm{H}_{28}^{+}$ $\left(\left[\mathrm{C}_{14} \mathrm{H}_{9}-\mathrm{C}_{48} \mathrm{H}_{19}\right]^{+}\right)$forms from $\mathrm{P}_{3}$ for experimental photodissociation Eq. (6), which will first converted into large PAHs. After that, the newly formed large PAHs will transformed into $\mathrm{C}_{64}^{+}$, or $\mathrm{C}_{62}^{+}$upon irradiation following with fully dehydrogenation, then with further $\mathrm{C}_{2}$ losing chemical pathways. The photochemical behavior of DC/9-vinylanthracene cluster cations are similar to fluorene cluster cations and large PAH cations (Zhen et al. 2015; Castellanos et al. 2018; West et al. 2018; Zhang et al. 2019).

In all, the calculation results are agree with the experimental results that observation in Fig. 2. Especially, except for dehydrogenation, particular photodissociation processes are observed that can change the nature of the carbon skeleton of PAH molecules, i.e., the $\mathrm{m} / z=772\left(\mathrm{CHCH}_{2}\right.$ loss with $1.7 \mathrm{eV}$ from $\mathrm{P}_{3}$ ) mass peak is determined as the main signal peak.

\subsection{DC/9-methylanthracene cluster cation system}

The DC/9-methylanthracene cluster cation system shown in Fig. 6 is similar to DC/anthracen and the DC/9-vinylanthracene cluster cations. $\mathrm{C}_{15} \mathrm{H}_{12} \mathrm{DDC}^{+}$is a cationic cluster of mono-9methylanthracene and DDC, connected by one $\mathrm{C}-\mathrm{C}$ single bond. Accordingly, the cationic clusters are $\left[\mathrm{C}_{15} \mathrm{H}_{12}-\mathrm{C}_{48} \mathrm{H}_{19}\right]^{+}(\mathrm{m} / \mathrm{z}=$ 787), $\left[\mathrm{C}_{15} \mathrm{H}_{12}-\mathrm{C}_{48} \mathrm{H}_{18}\right]^{+}(m / z=786),\left[\mathrm{C}_{15} \mathrm{H}_{12}-\mathrm{C}_{48} \mathrm{H}_{17}\right]^{+}$ $(m / z=785)$, and $\left[\mathrm{C}_{15} \mathrm{H}_{12}-\mathrm{C}_{48} \mathrm{H}_{16}\right]^{+}(\mathrm{m} / z=784)$. For the $\mathrm{C}-\mathrm{C}$ single bond in the $\mathrm{C}_{15} \mathrm{H}_{12} \mathrm{DDC}^{+}$cluster, one carbon from DDC is in $\mathrm{sp}^{2}$ hybridization, and the other carbon from 9methylanthracene is in $\mathrm{sp}^{3}$ hybridization with an additional $\mathrm{C}-\mathrm{H}$ bond. The experimental formation reaction pathways of the $\mathrm{C}_{15} \mathrm{H}_{12} \mathrm{DDC}$ group cluster cations are shown in Eq. (7).

As one typical example, we discuss below the formation pathway of $\left[\mathrm{C}_{15} \mathrm{H}_{12}-\mathrm{C}_{48} \mathrm{H}_{19}\right]^{+}$, which is a cationic cluster consisting of a neutral 9-methylanthracene and $\mathrm{C}_{48} \mathrm{H}_{19}^{+} \cdot \mathrm{C}_{48} \mathrm{H}_{19}^{+}$has a five-isomer structure and $\mathrm{C}_{15} \mathrm{H}_{12}$ has seven positions, which means that 35 reaction pathways are possible. We present one typical structure for $\mathrm{C}_{48} \mathrm{H}_{19}^{+}$and three typical position for $\mathrm{C}_{15} \mathrm{H}_{12}$ (as shown in Fig. 6A), with three more favorable possible reaction pathway and isomers $\left(\mathrm{P}_{1}, \mathrm{P}_{2}\right.$, and $\left.\mathrm{P}_{3}\right)$.

In Fig. 6A, we present the three possible reaction pathways of Eq. (7) and the optimized structures of $\left[\mathrm{C}_{15} \mathrm{H}_{12}-\mathrm{C}_{48} \mathrm{H}_{19}\right]^{+}$, that from $\left(\mathrm{C}_{48} \mathrm{H}_{19}^{+}\right.$and $\mathrm{C}_{15} \mathrm{H}_{12}$ to the cationic cluster of $\left[\mathrm{C}_{15} \mathrm{H}_{12}-\mathrm{C}_{48} \mathrm{H}_{19}\right]^{+}\left(\mathrm{P}_{1}, \mathrm{P}_{2}\right.$, and $\left.\mathrm{P}_{3}\right)$, respectively. Clearly, all the reactions are exothermic, with $-2.8 \mathrm{eV}$ for $\mathrm{P}_{1},-2.9 \mathrm{eV}$ for $\mathrm{P}_{2}$, and $-3.3 \mathrm{eV}$ for $\mathrm{P}_{3}$. The energy of the formation pathway of $\mathrm{P}_{3}$ is lower than that for $\mathrm{P}_{1}$ and $\mathrm{P}_{2}$. A possible reason may be that the single- $\mathrm{H} \mathrm{C}$ atoms in 9-methylanthracene are much more reactive than other C-atoms (Zhen et al. 2019). The formation energy for DC/9-methylanthracene cluster cations agrees with that of DC/9-vinylanthracene cluster cations, therefore we consider that the DC/9-methylanthracene cluster cations that we produced through ion-molecular reaction are a mixture of components that inlcudes all possible 35 different isomers.

In the subsequent dissociation pathway, we calculated four dissociation channel for $\left(\mathrm{C}_{15} \mathrm{H}_{12} \mathrm{DDC}^{+}, \mathrm{P}_{1}\right)$, as shown in Fig. 6B. The dissociation energy is $1.7 \mathrm{eV}$ for $\mathrm{H}$ loss from the aliphatic carbon, which is the dominant dissociation channel for $\mathrm{P}_{1}$. In contrast, $\mathrm{H}$ loss from the methyl group takes around $4.0 \mathrm{eV}$, $\mathrm{H}$ loss from the pure aromatic carbon rings located in the 9-methylanthracene molecules group takes around $5.2 \mathrm{eV}$, and 


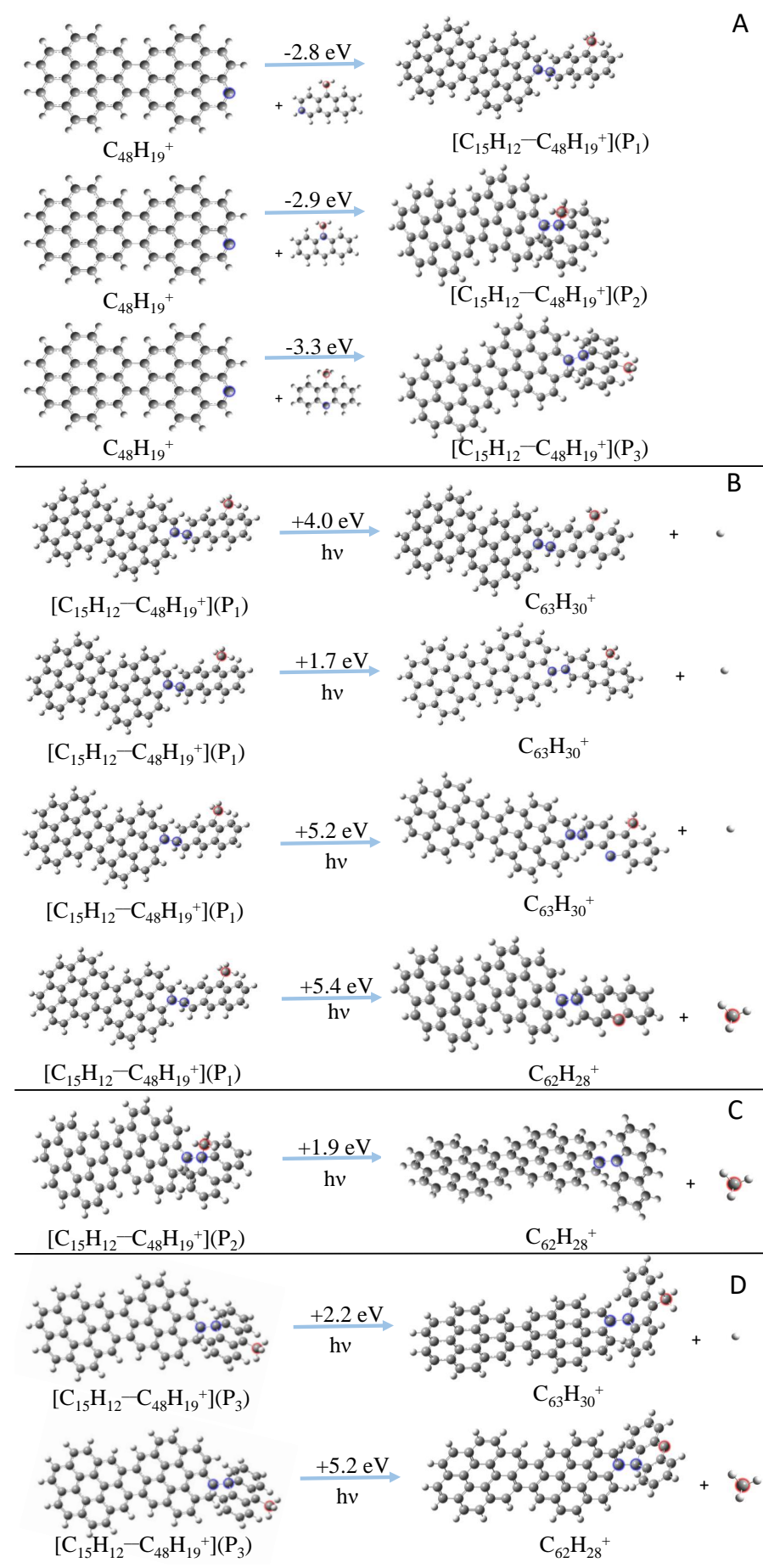

Fig. 6. Panel $A$ : formation reaction pathway for $\mathrm{C}_{15} \mathrm{H}_{12} \mathrm{DDC}^{+}$, e.g., $\mathrm{C}_{15} \mathrm{H}_{12} \mathrm{C}_{48} \mathrm{H}_{19}^{+}\left(\mathrm{P}_{1}, \mathrm{P}_{2}\right.$ and $\left.\mathrm{P}_{3}\right)$. Panel B: photodissociation pathway for $\mathrm{P}_{1}$. Panel $C$ : photodissociation pathway for $\mathrm{P}_{2}$. Panel D: photodissociation pathway for $\mathrm{P}_{3}$.

$\mathrm{CH}_{3}$ loss from the 9-methylanthracene molecules group takes around $5.4 \mathrm{eV}$. As shown in Fig. 6C, we also calculated one dissociation channel for $\left(\mathrm{C}_{15} \mathrm{H}_{12} \mathrm{DDC}^{+}, \mathrm{P}_{2}\right)$. The dissociation energy is $1.9 \mathrm{eV}$ for $\mathrm{CH}_{3}$ loss from aliphatic carbon, which is the dominant dissociation channel for $\mathrm{P}_{2}$. As shown in Fig. 6D, we calculated two dissociation channels for $\left(\mathrm{C}_{15} \mathrm{H}_{12} \mathrm{DDC}^{+}, \mathrm{P}_{3}\right)$. The dissociation energy is $2.2 \mathrm{eV}$ for $\mathrm{H}$ loss from the aliphatic carbon, which is the dominant dissociation channel for $\mathrm{P}_{3}$. In contrast, $\mathrm{CH}_{3}$ loss from the pure aromatic carbon rings that are located in the anthracene molecule group takes around $5.2 \mathrm{eV}$.

The lowest obtained dissociation energy for each DC/9methylanthracene cluster cation isomers, $\mathrm{H}$ loss with $1.7 \mathrm{eV}$ for $\mathrm{P}_{1}, \mathrm{H}$ loss with $2.2 \mathrm{eV}$ for $\mathrm{P}_{3}$ for dissociation Eq. (9), and $\mathrm{CH}_{3}$ loss with $1.9 \mathrm{eV}$ for $\mathrm{P}_{2}$ for dissociation Eq. (11), which agrees with the experimental results that showed that this is the dominant dissociation channel. The dissociation energy we obtained for DC/9-methylanthracene cluster cations is similar to that of DC/9-vinylanthracene, DC/anthracene, and to our previous result for fluorene cluster cations (Zhang et al. 2019). The continued dehydrogenation process for DC/9methylanthracene cluster cations, as shown in Fig. 6B-D, is $\mathrm{C}_{63} \mathrm{H}_{30}^{+}\left(\left[\mathrm{C}_{15} \mathrm{H}_{11}-\mathrm{C}_{48} \mathrm{H}_{19}\right]^{+}\right)$from $\mathrm{P}_{1}$ or $\mathrm{P}_{4}$ for the experimental photodissociation Eq. (10), $\mathrm{C}_{62} \mathrm{H}_{28}^{+}\left(\left[\mathrm{C}_{14} \mathrm{H}_{9}-\mathrm{C}_{48} \mathrm{H}_{19}\right]^{+}\right)$from $\mathrm{P}_{2}$ for the experimental photodissociation Eq. (12), which is first converted into large PAHs. After that, the newly formed large PAHs will transformed into $\mathrm{C}_{62}^{+}$upon irradiation following full dehydrogenation, then with further $\mathrm{C}_{2}$ losing chemical pathways. The photochemical behavior of DC/9-methylanthracene cluster cations are similar to fluorene cluster cations and large PAH cations (Zhen et al. 2015; Castellanos et al. 2018; West et al. 2018; Zhang et al. 2019). We do not observe $\mathrm{C}_{63}^{+}$ in the mass spectra in Fig. 3, which may suggest $\mathrm{C}_{63} \mathrm{H}_{30}^{+}$may involved some other dissociation channels.

The calculation result agrees with the experimental observation in Fig. 3. Especially, except dehydrogenation, particularly processes changing the nature of the carbon skeleton that the $m / z=772\left(\mathrm{CH}_{3}\right.$ loss with $1.9 \mathrm{eV}$ for $\left.\mathrm{P}_{2}\right)$ mass peak is determined as the main signal peak.

In addition, we note that to these newly formed species, such as $\mathrm{C}_{64} \mathrm{H}_{n}^{+}, n=[0-30]$ and $\mathrm{C}_{62} \mathrm{H}_{m}^{+}, m=[0-28]$ in Eqs. (4) and (6) for DC/9-vinylanthracene cluster cation system; $\mathrm{C}_{63} \mathrm{H}_{n}^{+}, n=[0-30]$ and $\mathrm{C}_{62} \mathrm{H}_{m}^{+}, m=[0-28]$ in Eqs. (10) and (12) for DC/9-methylanthracene cluster cation system and $\mathrm{C}_{62} \mathrm{H}_{n}^{+}$, $n=$ [0-28] in Eq. (14) for DC/anthracene cluster cation system, there is no attempt to predict which specific hydrogens in the original structure are the ones being lost or the resulting structure of the molecule after these multiple hydrogens are lost, more theoretical chemistry calculations are needed to confirm and give their structural information.

\subsection{Functional group effect}

We plot for the formation process in Fig. 7A the calculated exothermic energy of each DC/anthracene, DC/9-vinylanthracene, and DC/9-methylanthracene cluster cation isomer. The exothermic energies are very similar, around $-3.0 \mathrm{eV}$. This may suggest that the vinyl and methyl functional groups have a weaker effect on the evolution process of the PAH cluster systems, that is, substitute groups do not have a strong effect that would stabilize PAH cluster cations. All the polymerization between PAHs through ion-molecular reaction pathway is expected to have a similar exothermic energy. This also suggests that the formation of mixed multi-types of PAH cluster cations (e.g., $\left[\left(\mathrm{C}_{15} \mathrm{H}_{12}\right)\left(\mathrm{C}_{16} \mathrm{H}_{12}\right)-\right.$ $\left.\mathrm{C}_{48} \mathrm{H}_{18}\right]^{+}$) in the gas phase is possible. More experiments are required to address the formation and evolution of $\mathrm{PAH}$ reactions with multi-types of small PAHs.

We plot the subsequent dissociation pathway that is initiated by the laser irradiation in Fig. 7B for the calculated lowest dissociation energy of each DC/anthracene, DC/9-vinylanthracene, and DC/9-methylanthracene cluster cation isomers. The photoevolution of DC/anthracene cluster cations has been presented in Zhen (2019). The DC/9-vinylanthracene cluster cations 

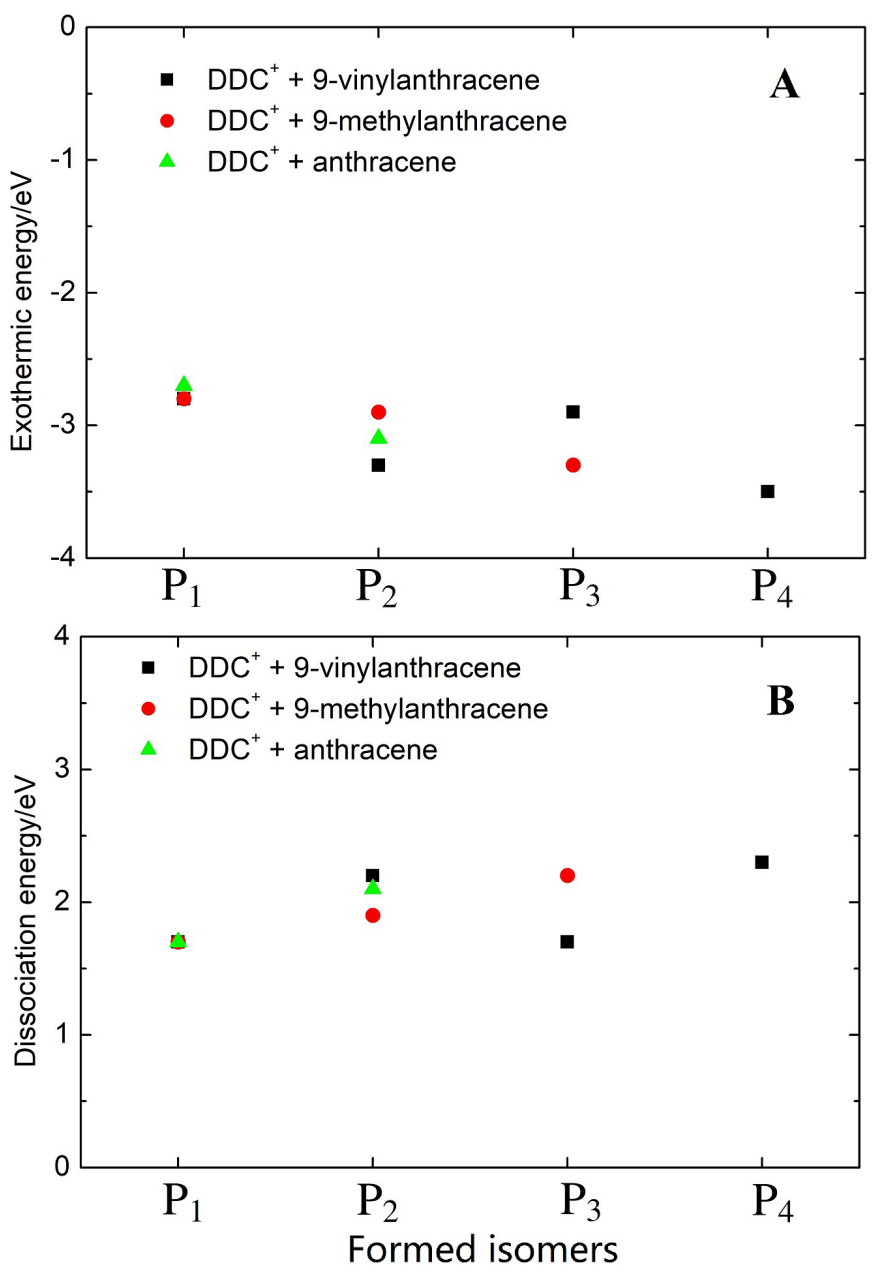

Fig. 7. Panel A: calculated exothermic energy of each DC/anthracene, DC/9-vinylanthracene, DC/9-methylanthracene cluster cations isomer. Panel B: calculated lowest dissociation energy of each DC/anthracene, DC/9-vinylanthracene, DC/9-methylanthracene cluster cations isomer.

are shown in Fig. 2B, and the DC/9-methylanthracene cluster cations are shown in Fig. 3B. With laser irradiation, they all have a very complex fragmentation process (e.g., dehydrogenation, or $-\mathrm{CH}_{3}$ or $-\mathrm{CHCH}_{2}$ unit losses), and result as more aromatic molecular properties, and the substituted group plays an important role in the photolysis process. The dissociation energy of $\mathrm{H}$-loss is generally $\sim 2.0 \mathrm{eV}$, and that of $-\mathrm{CHCH}_{2}$ or $-\mathrm{CH}_{3}$ loss is $\sim 1.7 \mathrm{eV}$ from the aliphatic carbon of PAHs cluster cations. This is lower than the calculated bond energy of the DC/anthracene, DC/9-vinylanthracene, or DC/9-methylanthracene cluster cations $(\sim 3.0 \mathrm{eV})$. This result agrees with the experimental observation. We stress here that the derived dissociation energy (Fig. 7B) for all the dehydrogenation and functional group loss steps is lower than the dehydrogenation energy barrier of pure PAHs (Chen et al. 2015; Croiset et al. 2016; Castellanos et al. 2018; West et al. 2018).

However, the functional group causes the structure of formed PAH clusters, or the final formed PAHs become more uniform and divers. The structure of the PAH clusters that formed initially becomes more divers, as shown in Figs. 4-6, especially with functional groups.

We present in Fig. 8 three possible formed large PAHs. The upper panel shows uniform behavior, and the lower two panels show divers behavior. One typical example of formed large PAHs from $\mathrm{C}_{14} \mathrm{H}_{12} \mathrm{DDC}^{+}\left(\mathrm{P}_{2}\right), \mathrm{C}_{16} \mathrm{H}_{12} \mathrm{DDC}^{+}$(after $\mathrm{P}_{3}$ loss
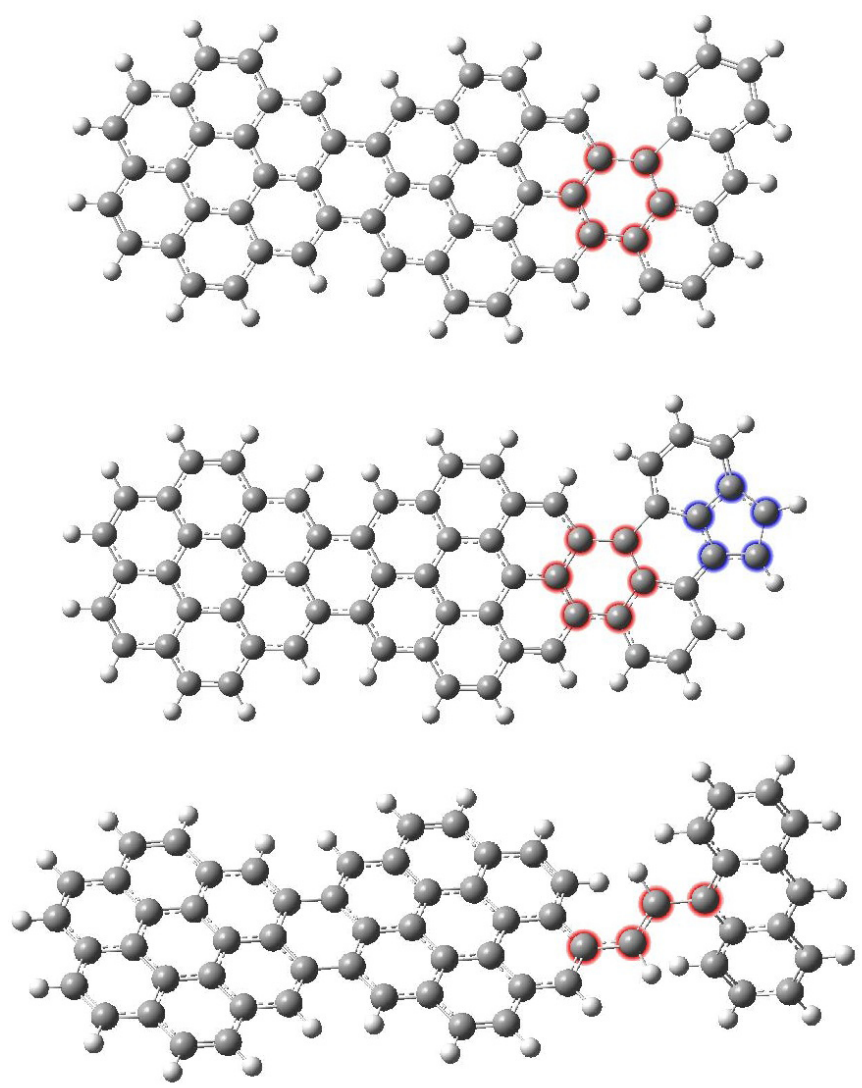

Fig. 8. Upper $P A H$ : formed from $\mathrm{C}_{14} \mathrm{H}_{12} \mathrm{DDC}^{+}\left(\mathrm{P}_{2}\right), \mathrm{C}_{16} \mathrm{H}_{12} \mathrm{DDC}^{+}$ (after $\mathrm{P}_{3}$ loss $\mathrm{CHCH}_{2}$ ) or $\mathrm{C}_{15} \mathrm{H}_{12} \mathrm{DDC}^{+}$(after $\mathrm{P}_{2}$ loss $\mathrm{CH}_{3}$ ). Middle PAH: formed from $\mathrm{C}_{16} \mathrm{H}_{12} \mathrm{DDC}^{+}\left(\mathrm{P}_{2}\right)$. Lower PAH: formed from $\mathrm{C}_{16} \mathrm{H}_{12} \mathrm{DDC}^{+}\left(\mathrm{P}_{4}\right)$.

$\mathrm{CHCH}_{2}$ ) or $\mathrm{C}_{15} \mathrm{H}_{12} \mathrm{DDC}^{+}$(after $\mathrm{P}_{2}$ loss $\mathrm{CH}_{3}$ ) is shown in Fig. 8 (upper panel). The red carbon ring stands for the intramolecular photoaromatic process between $\mathrm{C}_{48} \mathrm{H}_{19}^{+}$and the other adducted molecules. One typical example of formed large PAHs from $\mathrm{C}_{16} \mathrm{H}_{12} \mathrm{DDC}^{+}\left(\mathrm{P}_{2}\right)$ is shown in Fig. 8 (middle panel). The red and blue carbon rings stand for the newly formed c-rings. It is interesting that $\left[\mathrm{C}_{16} \mathrm{H}_{12}-\mathrm{C}_{48} \mathrm{H}_{19}\right]^{+}, \mathrm{P}_{2}$, and $\mathrm{P}_{4}$ contain two dehydrogenation centers for further dehydrogenation. As shown in Fig. 8 (middle panel), the red carbon ring stands for the intramolecular photoaromatic process between $\mathrm{C}_{48} \mathrm{H}_{19}^{+}$and 9-vinylanthracene molecules, and the blue carbon ring stands for the intermolecular photoaromatic process in 9-vinylanthracene molecule itself. One other example of formed large PAHs from $\mathrm{C}_{16} \mathrm{H}_{12} \mathrm{DDC}^{+}\left(\mathrm{P}_{4}\right)$ is shown in Fig. 8 (lower panel), which contains a hydrated carbon chain $(\mathrm{C}-\mathrm{CH}-\mathrm{CH}-\mathrm{C})$ that maybe retain its carbon chain, or lost and further convert to large PAHs, the four red carbon rings stand for the hydrated carbon chain (bridge) in the PAHs, which represents one important structure in hydrogenated amorphous carbon (HAC), and offers an approach to the HAC formation process in the ISM (Tielens 2008).

\section{Astronomical implications}

Most PAH clusters in the ISM are probably chemically bound because of their reactivity, and the astronomical PAH population is expected to exist in different charge and (de)hydrogenation states depending on the environment. They therefore influence the formation of other species through ion-molecule reaction (Tielens 2013; Zhang et al. 2019). Consequently, we 
experimentally and theoretically studied the formation processes that result in a series of large PAH clusters. Gas-phase reactions between PAH cations (e.g., DDC or DHBC) and PAHs (e.g., anthracene, 9-vinylanthracene or 9-methylanthracene) readily occur (Zhen 2019; Zhen et al. 2019). Based on the obtained results from quantumchemistry calculations, we demonstrate the formation process of large PAH cluster cations, which helps to understand the effect of the functional group on their formation behaviors.

The rate of PAH cluster formation might be a bottleneck in the formation process of larger PAHs or carbonaceous dust grains in the ISM, and cluster of PAHs are believed to be a key step in the formation of soot in terrestrial combustion processes. However, the binding energy for DC/anthracene, DC/9vinylanthracene, and DC/9-methylanthracene cluster cations is around $\sim 3.0 \mathrm{eV}$, which means that the fundamental reactions between PAHs species (e.g., cationic+neutral, exothermic reaction) are able to produce a probably significant class of cosmic molecules in the ISM. Clearly, when conditions are favorable, these molecules can be formed efficiently. These molecules have a complex configuration, as well as an internal composition, and are large, which can be a good example and first formation step of carbonaceous dust grains in the ISM (Kroto et al. 1985; Henning \& Salama 1998; Jäger et al. 2009, 2011). This can offer a good approach to carbonaceous dust grains, which provide a basic understanding (e.g., composition and structural properties) about the grain formation processes in the gas phase (Bohme 1992; Clayton et al. 1999; Petrie \& Bohme 2009).

In addition, the importance of functionalized PAHs for the formation of these larger cluster cations is limited if the lifetime of the functionalized PAHs is very short in the ISM. Because the functional group is easily lost by UV irradiation (Zhen et al. 2016; Chen et al. 2018), functionalized PAHs would not seem to be particularly important in energetic regions where the AIBs typically appear in the ISM (Li \& Draine 2012). These species contain highly reactive reaction centers because of the functional groups, which facilitates molecular adduct aggregation, as shown in Figs. 5A and 6A. More isomers are therefore formed in the DC/9-vinylanthracene and DC/9methylanthracene cluster cation system. After cluster formation, the functional groups still play an important role in the photoisomerization and photodissociation of functional PAH clusters, as shown in Figs. 5B-E and 6B-D. More experiments are required for a broader range of functional groups, such as methoxy $\left(-\mathrm{OCH}_{3}\right)$, amino $\left(-\mathrm{NH}_{2}\right)$, cyano/isocyano $(-\mathrm{CN},-\mathrm{NC})$, acid $(-\mathrm{COOH})$, or hydroxyl $(-\mathrm{OH})$ (Hollenbach \& Tielens 1999 ; Bernstein et al. 2002), to assess whether this can be used to quantitatively probe the contribution of these chemical routes toward the complexity of regions that are illuminated by strong stellar radiation fields in space.

We studied the photochemically evolution of PAH clusters. These PAH clusters are more fragile in the beginning. Partial PAH clusters will lose their functional group and then convert into large PAHs. Different from the energetic ions (as an energydriving source), they induce intracluster reactions to form large molecules, that is, they are ion driven (Zettergren et al. 2010, 2013; Delaunay et al. 2015). The experimental results we presented here provide further insight into the photoevolution process of large molecules in the ISM. New larger molecules can be built with stronger irradiation by UV photons (as an energydriving source), that is, they are photo driven. The conversion is suggested to take place in the areas of high luminosity where PAH clusters absorb multiple photons. Multile photon absorp- tion leads to dehydrogenation of PAHs, followed by polymerization of smaller PAHs (Hollenbach \& Tielens 1999).

Furthermore, after photochemical process, different $\mathrm{PAH}$ clusters will form the same PAHs. We show one typical example of large PAHs $\left(\mathrm{C}_{62} \mathrm{H}_{26}\right)$ in the upper panel of Fig. 8. These can form from DC/anthracene cluster cations $\left(\mathrm{C}_{14} \mathrm{H}_{12} \mathrm{DDC}^{+}\right.$, $\left.\mathrm{P}_{2}\right)$, DC/9-vinylanthracene cluster cations $\left(\mathrm{C}_{16} \mathrm{H}_{12} \mathrm{DDC}^{+}\right.$, after $\mathrm{P}_{3}$ loss $\mathrm{CHCH}_{2}$ ), or DC/9-methylanthracene cluster cations $\left(\mathrm{C}_{15} \mathrm{H}_{12} \mathrm{DDC}^{+}\right.$, after $\mathrm{P}_{2}$ loss $\left.\mathrm{CH}_{3}\right)$. Therefore, we may conclude that larger PAHs or possibly better with same or similar carbon frame PAHs (Fig. 8), will be formed from the photoevolution of different types of large PAH cluster that may exist in the ISM.

\section{Conclusions}

We presented the experimental and theoretical study of the formation process of the covalently bonded large $\mathrm{PAH}$ cluster cations DC/9-vinylanthracene $\left(\mathrm{C}_{16} \mathrm{H}_{12}\right)$ and DC/9methylanthracene $\left(\mathrm{C}_{15} \mathrm{H}_{12}\right)$ in the gas phase, and studied their photodissociation behaviors. We showed with quantumchemical calculations that these newly formed cluster species can be quite stable (the binding energy is $\sim 3.0 \mathrm{eV}$ for DC/anthracene, DC/9vinylanthracene, and DC/9-methylanthracene cluster cations). Subsequent photoprocessing either directly converts these PAH cluster cations into their most stable forms, that is, large PAHs, or removes their functional groups and then converts these $\mathrm{PAH}$ cluster cations into their most stable forms, that is, large PAHs.

From an astrochemical perspective, together with the DC/anthracene $\left(\mathrm{C}_{14} \mathrm{H}_{10}\right)$ cluster cations we studied previously (Zhen 2019), we experimentally and theoretically revealed a general formation process for covalently bonded PAH cluster cations in the ISM. As initial precursor molecules, the formation mechanism (gas-phase condensation) and photodissociation behavior we obtained from covalently bonded DC/PAH cluster cations can be generalized and provides a reasonable explanation for the formation and evolution of large molecules in space. Astronomical models for (covalently bonded) PAH cluster evolution in the ISM based upon our results will help to elucidate whether the formation process can indeed occur, and our results act as an important model to understand the physical and chemical processes involved in the formation and evolution of carbon dust grains in space.

Acknowledgements. This work is supported by the Fundamental Research Funds for the Central Universities and from the National Science Foundation of China (NSFC, Grant No. 11743004 and Grant No. 11421303).

\section{References}

Allamandola, L. J., Tielens, A. G. G. M., \& Barker, J. R. 1989, ApJS, 71, 733 Andrews, H., Boersma, C., Werner, M. W., et al. 2015, ApJ, 807, 99

Basiuk, V. A., \& Tahuilan-Anguiano, D. E. 2019, Chem. Phys. Lett., 722, 146 Becke, A. D. 1992, J. Chem. Phys., 96, 2155

Bernstein, M. P., Sandford, S. A., Allamandola, L. J., et al. 1999, Science, 283, 1135

Berné, O., Joblin, C., Deville, Y., et al. 2007, A\&A, 469, 575

Bernstein, M. P., Elsila, J. E., Dworkin, J. P., et al. 2002, ApJ, 576, 1115

Bohme, D. K. 1992, Chem. Rev., 92, 1487

Castellanos, P., Candian, A., Zhen, J., Linnartz, H., \& Tielens, A. G. G. M. 2018, A\&A, 616, A166

Cherchneff, I., Barker, J. R., \& Tielens, A. G. G. M. 1992, ApJ, 401, 269

Chen, T., Gatchell, M., Stockett, M. H., et al. 2015, J. Chem. Phys., 142, 144305 Chen, T., Zhen, J., Wang, Y., Linnartz, H., \& Tielens, A. G. G. M. 2018, Chem. Phys. Lett., 692, 298

Chuvilin, A., Kaiser, U., Bichoutskaia, E., Besley, N. A., \& Khlobystov, A. N. 2010, Nat. Chem., 2, 450 
Clayton, D. D., Liu, W. H., \& Dalgarno, A. 1999, Science, 283, 1290

Cook, A. M., Ricca, A., Mattioda, A. L., et al. 2015, ApJ, 799, 14

Croiset, B. A., Candian, A., Berné, O., \& Tielens, A. G. G. M. 2016, A\&A, 590, A26

Dunk, P. W., Adjizian, J. J., Kaiser, N. K., et al. 2013, Proc. Natl. Acad. Sci. 110, 18081

Delaunay, R., Gatchell, M., Rousseau, P., et al. 2015, J. Phys. Chem. Lett., 6 1536

Frisch, M. J., Trucks, G. W., Schlegel, H. B., et al. Gaussian 16 Revision e. 01 (Gaussian Inc.)

Frenklach, M., \& Feigelson, E. D. 1989, ApJ, 341, 372

Grimme, S., Ehrlich, S., \& Goerigk, L. 2011, J. Comp. Chem., 32, 1456

Geballe, T., Tielens, A. G. G. M., Allamandola, L. J., Moorhouse, A., \& Brand, P. W. J. L. 1989, ApJ, 341, 278

Henning, T., \& Salama, F. 1998, Science, 282, 2204

Hollenbach, D. J., \& Tielens, A. G. G. M. 1999, Rev. Mod. Phys., 71, 173

Jäger, C., Mutschke, H., Henning, T., \& Huisken, F. 2011, in EAS Publ. Ser., eds. C. Joblin, \& A. G. G. M. Tielens, 46, 293

Jäger, C., Huisken, F., Mutschke, H., Llamas Jansa, I., \& Henning, T. 2009, ApJ, 696, 706

Kroto, H., Heath, J., O’Brien, S., Curl, R., \& Smalley, R. 1985, Nature, 318, 162

Kofman, V., Sarre, P. J., Hibbins, R. E., ten Kate, I. L., \& Linnartz, H. 2017, Mol. Astron., 7, 19

Lee, C., Yang, W., \& Parr, R. G. 1988, Phys. Rev. B, 37, 785

Li, A., \& Draine, B. T. 2012, ApJ, 760, L35

Montillaud, J., Joblin, C., \& Toublanc, D. 2013, A\&A, 552, A15
Peeters, E., Bauschlicher, Jr., C. W., Allamandola, L. J., et al. 2017, ApJ, 836, 198

Petrie, S., \& Bohme, D. K. 2009, ApJ, 540, 869

Pietrucci, F., \& Andreoni, W. 2014, J. Chem. Theory Comput., 10, 913

Pilleri, P., Montillaud, J., Berné, O., \& Joblin, C. 2012, A\&A, 542, A69

Puget, J. L., \& Léger, A. 1989, ARA\&A, 27, 161

Rapacioli, M., Joblin, C., \& Boissel, P. 2005, A\&A, 429, 193

Sellgren, K. 1984, ApJ, 277, 623

Tielens, A. G. G. M. 2005, The Physics and Chemistry of the Interstellar Medium, 1st edn. (Cambridge: Cambridge Univ. Press)

Tielens, A. G. G. M. 2008, ARA\&A, 46, 289

Tielens, A. G. G. M. 2013, Rev. Mod. Phys., 85, 1021

Walsh, R. 2008, Chem. Soc. Rev., 37, 686

West, B., Castillo, S. R., Sit, A., et al. 2018, Phys. Chem. Chem. Phys., 20, 7195

Zettergren, H., Johansson, H. A. B., Schmidt, H. T., et al. 2010, J. Chem. Phys., 133,104301

Zettergren, H., Rousseau, P., Wang, Y., et al. 2013, Phys. Rev. Lett., 110, 185501

Zhang, W., Si, Y. B., Zhen, J., Chen, T., Linnartz, H., \& Tielens, A. G. G. M. 2019, ApJ, 872, 38

Zhen, J. 2019, A\&A, 623, A102

Zhen, J., Castellanos, P., Paardekooper, D. M., et al. 2015, ApJ, 804, L7

Zhen, J., Castellanos, P., Linnartz, H., \& Tielens, A. G. G. M. 2016, Mol. Astron., 5,1

Zhen, J., Candian, A., Castellanos, P., et al. 2018, ApJ, 854, 27

Zhen, J., Zhang, W., Yang, Y., \& Zhu, Q. 2019, MNRAS, 486, 3259 